\title{
Art as an Asset for Wealth Management
}

\author{
Jean-Francois Verdie*, Miloud Guermatha \\ Economics and Finance Department, TBS Business School, Toulouse, France \\ Email address: \\ jf.verdie@tbs-education.fr (Jean-Francois V.), m.guermatha@tbs-education.ma (Miloud G.) \\ ${ }^{*}$ Corresponding author
}

To cite this article:

Jean-Francois Verdie, Miloud Guermatha. Art as an Asset for Wealth Management. American Journal of Theoretical and Applied Business. Vol. 7, No. 1, 2021, pp. 1-7. doi: 10.11648/j.ajtab.20210701.11

Received: January 5, 2021; Accepted: January 18, 2021; Published: January 25, 2021

\begin{abstract}
Throughout time, artwork has been a luxury commodity associated with aesthetic appeal, affluence and power. While the primary benefactors of art industry have always been the artists themselves and intermediaries that link them to buyers, the art industry is now emerging as a financial investment plan especially among the affluent members of the community who are in position to invest into pleasure assets. This because art generally appreciates with value at a steady rate which is lucrative and the industry has expanded with time as more key players join in to optimize on the gains. While it is a legitimate investment venture, the art industry is characterized by volatility, illiquidity and opacity which discourage many investors. In addition, the risk taken rarely measures up to the reward gained. This is considering the high initial cost of investing and the time it takes for the artwork to gain considerable value for adequate profit to be gained. This leaves the art investment to a select few especially the affluent that looking to diversify their investment portfolio especially for long term investments. This article weighs the rewards of investing in artwork as an asset against the risks involved and justifies whether investment in art should be an investment option.
\end{abstract}

Keywords: Art, Investment, Risk and Return, Wealth Management

\section{Introduction}

Human beings possess a unique ability to express themselves through various means which enhances communication and connection amongst one another. However, these abilities are often amplified in a select group of people that are able to hone their creative skills and produce art. Art is distinctly human and takes on various forms with regards to the human senses whether visual, auditory or related to touch. Whether an individual possesses creative skills or not it is easy to appreciate good art form. Primarily, art especially of the visual form is often aesthetically pleasing to look at and a symbol of beauty. In some instances, the art form could be puzzling to the average human mind which is a form of appeal in itself. Art is also appreciated for the emotions it evokes. Reutter [14] concludes that these properties are what make art a consumable entity in the human society. All art forms are a symbolization of beauty, human emotion and power which are all properties that human beings want to be associated with. Stavnichaya [15] observes that the art industry has recently emerged as an area of investment and wealth management. This is because art remains a consumable entity despite of changing times and the ability to associate it with affluence. As mentioned, creative skills are a limited range of capabilities and only few individuals are endowed with them. This makes artistic products a rare commodity that can be commercialized purely as a pleasure product. Consequently, this provides unique opportunity for investors to sponsor art or even amass art pieces as a form of capital asset. These art forms can later be sold off when they have appreciated in value. While human beings are always pegged on art in every moment through time, their taste change based on their environment and what is in fashion. This means that art and what is considered good art form is extremely volatile as this greatly depends on the consumers. What might be beautiful today may have no meaning in a few years. This raises the stakes for investors in the art industry as wealth can easily be created by destroyed by a few wrong moves. This paper analyses the art industry as an investment option with consideration of the rewards, the risks and whether it should be a viable investment option. 


\section{Historical Significance}

Art has always been a unique human trait whose inherent value has remained consistent through time. A study of art history by Reutter [14] shows that art has evolved throughout time and has been heavily influenced by geographical location of the artist, societal and environmental influence making it an extremely subjective product. The author adds that artists in the past were revered members of the community whose societal standing had to be as good as their creative skills for them to be recognized as good artists [14]. In fact, artists often belonged to their own societal class, were highly ranked and in some instances, even associated with royalty. This made art form a precious commodity in past times and sometimes a commodity that only the rich could afford. It is therefore accurate to deduce that trade in art has been in existence as long as artists have been members of the human society.

Reutter [14] traces back art trade to as early as 300 B.C when Phoenicians would sail to foreign lands to trade with people of Mediterranean and European lands. The author lists that the products the Phoenicians would trade were their artistic ornamental objects consisting of bronze, glass and ivory material [14]. Since the Phoenicians had insufficient food to sustain themselves, they traded in their crafts for essential products with foreigners. This implies that an established art trade market was already in existence at the time and there was a commendable demand for art. A similar scenario existed in Ancient Rome as early as the $8^{\text {th }}$ century B.C where the Italian population consumed Grecian art pieces which would be imported for sale [14]. Research heavily suggest that there might have been auctions held after the importation of these art pieces which might explain the existence of art auctions in modern times. For artists at the time, this was a legitimate way of making a living as they belonged to inferior economic class but their products were in high demand among the affluent members of the society. The artist's identity was of little consequence at the time.

In the middle ages, there was a heightened demand for artwork especially by the Clergy and members of the royal court. During this time, Preziosi [9] points out that the patronage culture became prominent as artists would be commissioned to create unique art pieces at a small fee. The author highlights that deep appreciation for art is particularly evident in Roman culture which is credited with the birthing of various renowned artists and art movements [9]. Throughout history, art was the pinnacle of Italian culture, beauty, power and religious beliefs. The affluent members of the community often hired artists to create pieces for them and they dictated what they wanted the art form to look and feel like. This would give rise to the prominence of fine art such as paintings, sculptures and architectural designs whose inherent value lies in its aesthetic appeal and imaginative concept [9]. A similar culture existed in Asia where artists where dynasties encouraged the flourishment of art [2]. While the existence of a primary market for art during the Middle Ages is well documented, there is little information on the existence of a secondary market which would shed light on whether art was a form of financial investment at the time. However, the possibility cannot be ruled out as there were brokers whose role was to procure art pieces for the affluent for which the brokers would get a small commission out of it [14]. The consumption of art, especially fine art, was primarily for the appreciation of its aesthetic appeal and as a demonstration of affluence and power. The rich patrons of Italy might not have been necessarily concerned with the financial returns from their art pieces but were rather focused on the immortalization of their legacy through art and the possession of aesthetically pleasing pieces. Needless to say, some of the most prized art pieces in the world are from the Middle Ages as their value have dramatically appreciated over time and are set to continue increasing in value even in future.

\section{Modern Art Industry}

The end of the Middle Ages ushered in the era of the modern art industry. At the end of the $16^{\text {th }}$ century there was a marked increase in the demand for art. Reutter [14] credits this observation is due to the Industrial Revolution which led to the rise of a new class of wealthy merchants, industrialists and investors who sought to expand their tastes into pleasurable goods. Among their new taste was the need for art which has always been a symbol of affluence and refined taste. Art therefore stopped being exclusive to the aristocrats and the clergy members. The demand for art gave room for the emancipation of artists from depending on patronage to being able to find their own societal standing where they could trade their work for money.

While the members of the society simply sought art for aesthetic appeal and painters were trying to make a living out of their work, a special group of intermediaries arose whose sole purpose was to link painters to their market [14]. These brokers sometimes doubled as painters themselves and had collections of work from various artists which they sold to the public. This is an early form of the collection of art as an asset that could be used to accumulate wealth. To be a successful fine art dealer, an individual had to have a trained eye for good art. The occupation also required intimate knowledge of current trends which were often volatile and constantly changing. Fine art dealers would also often take on young and unknown painters who they nurtured and gave exposure. Reutter [14] concludes that through the works of their protégés, intermediaries would earn money for extended periods of times, sometimes decades and through which they would earn back their investments. It goes without mentioning that this only worked if the artist's work appreciated in value due to refined skills. In addition, success also depended on adequate exposure of an artist's work to the public. This gave rise to exhibition centers especially in renowned artistic centers such as France and Netherlands which were hosts to some of the most popular exhibition centers at the height of the $17^{\text {th }}, 18^{\text {th }}$ and $19^{\text {th }}$ centuries [9]. Among the most prominent exhibition owners is Paul 
Durand-Ruel who was an established fine arts dealer based in France and England who is credited with popularizing the Impressionist style of art in Europe and even in the USA through exhibitions and galleries [14]. Durand-Ruel managed to accumulate wealth by investing in his artists' works and popularizing them to novel markets. He managed to achieve this by having a keen eye for fine art, especially by scouting for new talent that he knew would appreciate in value with time. In addition, Durand-Ruel had a balance of astute business practices which complemented his taste in art.

The modern art industry is also characterized by its heterogeneity through the existence of old art works especially from renowned Old Master of the Middle ages, works from the $18^{\text {th }}$ and $19^{\text {th }}$ centuries and works from more modern artists whose numbers continue to grow [6]. Artists have managed to mostly emancipate themselves from the patronage culture. It is also important to note that art value remains subjective and is mostly controlled by societal factors. However, Coslor and Spaenjers [3] remark that the market has considerably grown up and the society is more recipient to all forms of art no matter how new it is. This can be seen with the rise contemporary genre of art after decades of being decades of contention [6]. Over time, the art industry has consolidated its legitimacy which is primarily driven by the demand for art by art enthusiasts or affluent people who simply want to possess art for aesthetic appeal and recently, investors looking to grow their wealth by investing in artwork [12]. The industry is a source of livelihood for various types of artists who benefit from direct sales or rentals in galleries and exhibitions. In addition, the role of intermediaries has passed the test of time as they still play a key role in linking artists and art investors and buyers. They remain reputable for their ability to authenticate fine art and good artists whose value will appreciate over time. Additional key players are art critics, consultants, students, teachers and even media houses who control the stakes of the art industry and influence trends. Good artwork has remained a luxury item over time despite of modern influences and digitalization.

\section{Art as an Asset}

The popularity of the art industry as a unique site for financial investment and wealth management has continued to grow with time. Artwork has always been able to sell based on perceived aesthetic value. Consumers are generally attracted to beauty, emotion, innovation and eccentricity which drive the market value of artwork. An important additional factor that influences the market value of an art form is the artist, more so the reputation of the artist. Reutter [14] observes that unlike in modern times where craftsmen generally belonged to the backstage when it came to their work, the modern art industry is heavily influenced by the popularity of the artist. Consumers are likely to buy artwork if they have heard of the artist's name and even they can attach personality to the name with regards to innovation, eccentricity and even profanity. Generally, art has two types of markets, primary and secondary. Angelini and Castellani (2018) highlight that the primary markets involve direct purchase of art from the artists which can be done by brokers, dealers or direct consumers. The authors emphasize that for investment purposes, the stakes are within the secondary market which involves trading of artwork that has been traded before [5]. The initial value of an art piece in the primary market is important in determining its success in the secondary market but is also subject to change. It is therefore possible to overestimate or underestimate the economic value of artwork if an individual relies on the primary market value of the artwork. According to Coslor and Spaejers [3], a more dependable way of evaluating the value of artwork is by analyzing the demand through galleries and exhibitions which control a significant portion of the secondary market. Gerlis [14] opines that the value of an artwork is likely to appreciate in value if it is already established in the secondary market which is harder to crack. Given the astronomical prices that art pieces carry, overestimation of value can be devastating for an investor because it implies that the art will only depreciate in value over time. Key players in the secondary market that contribute to the market value of artwork are art critics, consultants, exhibitionists and even institutions such as museums and schools [13]. These key players have the potential of upregulating the market value of artwork and in some instances, even downregulating it. This is because they often earn their reputation in the art industry for having a keen eye for fine art, being able to scout for talent and estimating the future value of the artwork. While the public's taste is equally important and should be taken into account, it has proven to be erratic and easily influenced with regards to locality, the environment and other opinions. Entry into the art industry for investment purposes requires intimate knowledge of the inner workings of the industry and how all the above mentioned factors influence the market value of art.

The art industry has earned a reputation for its complexity due to the influence and interplay of all the above mentioned factors that affect art value. Despite of the complex nature of the art industry, art investment only continues to grow as the affluent members of the society continue to look into pleasure assets as a form of investment. As much as artwork is still purchased for aesthetic appeal, Xiang [16] observes that investment gains have become a major influencing factor in the purchase of artwork for both collectors and investors alike. This means that unless the buyer believes that the artwork will appreciate in value with time, they are unlikely to buy it. While this culture has been the norm for middle men in the past, the same now applies to the affluent consumer looking to make a luxury purchase of artwork. Xiang [16], reasons that the heightened interest in art investment could explain the boom in the art industry which has nearly doubled over the past decade in the USA alone. The author adds that similar trends have been reported in Asia and Europe with China holding a giant share of almost $35 \%$ of the auction market for artwork [16]. The industry is generally expected to the same trend over the next few years. 
Art qualifies to be an asset because it generally appreciates with value over time. According to Renneboog and Spaenjers [13], the standard appreciation rate for artwork is $4 \%$ per annum from 1995 to 2010 . This is a steady and dependable appreciation value. Like any other asset, the value of art is determined by the economic environment which can either be negative as in the event of regression or it can be positive in the event of an economic boom. In comparison to other assets, Gerlis [6], reports that artwork investment has proven to be steady despite of economic disruptions. The author adds that market value of art can be influenced by art movements which are periodic times through which a particular style dominates and new artists in tune with the style are birthed [6]. The influence of art movements on the market value of art can be seen during the Cubanism, Pop Art and Contemporary art movements have popularized the artworks from these periods hence driving up their market value [14].

Art investment became a serious venture in the 1970s when there was increased interest in the financial gains from artwork. Affluent members of the society have since been the greatest benefactors of the venture. According to Frye (2018), this observation is owed to the ultra-high pricing of artwork which locks out a large pool of investors. The rich are however easily capable of purchasing expensive artwork, sometimes in huge collections, purely for the purpose of financial gains. Frye [5], highlights that a trend that arose in the late $20^{\text {th }}$ century is the establishment of art funds. The author details that art funds are created by a pool of investors who pool in their resources for the purchase of artwork in huge collections that cannot be purchase individually due to financial limitation [1]. The collection of artwork is then removed from the market, stored for a limited period of time, for at least five years before being introduced back to the market after gaining a considerable amount of value. Similarly, art exchanges have been set up in countries like China which can be likened to the stock exchange through which artists are connected to buyers [2]. In comparison, art exchanges allow even investors of modest financial capabilities to invest in art. The management companies that run art exchanges work with investors and allow them to benefit from the buying, selling and management of artwork. Art funds and art exchanges are commonly referred to as art investment vehicles due to the pooling of resources from different investors and the appointment of managers to manage the investment. However, Gerlis [6] points out that most of the activity in artwork sales is due to auctions which account for nearly $50 \%$ of all revenue gained from art. Auctions are often run by art dealers and for a wide range of buyers who include gallery owners, direct consumers and even institutions.

\section{Prospects}

A study of the art industry shows that it is in boom and continues to steadily grow. Gerlis [6] describes the art industry to be the epitome of elegance and sophistication which the affluent want to be associated with. Frye [5] observes that the increasing number of the ultra-rich members of the society only serves to drive the art industry as the demand for artwork continues to grow. The ultra-rich are typically defined as individuals with over $\$ 30$ million in assets. A report on the asset portfolio by Gerlis [6] shows that $28.2 \%$ of their wealth is kept in cash, $26.1 \%$ in public equities, $20 \%$ in real estate, $15 \%$ in fixed income and $10 \%$ in alternate assets which include art. Out of the total portfolio of alternative assets which include gold, artwork and even wines, artwork makes up close to $20 \%$ which is a significant portion. This accounts to $4 \%$ of total assets invested in artwork. With time, it is expected that the art industry, especially with regards to investment is only set to grow. This is primarily due to the steady increase in number of the rich in the society especially in developed parts of the world such as USA and China. As an alternative asset, artwork performs moderately well because it doubles as a luxury commodity and a capital asset with a consistent appreciation value. An increasing number of people continue to develop interest in artwork when they can afford to and thus investment in the field will automatically be rewarding.

Globally, Gerlis [6] estimates that the art industry is $\$ 400$ billion and on average generates close to $\$ 65$ Billion in sales annually. The growth in sales in the art industry has steadily grown over the past few decades and the growth has remained seemingly unaffected by economic disruptions. This steady growth and profitability makes art investment even more attractive for collectors and investors as they get the double benefit of owning a pleasure commodity that and a capital asset that appreciates in value with time. As mentioned earlier, artwork has a steady appreciation rate of at least $4 \%$ per annum and has remained consistent over time.

The chart below represents the asset allocation based on the report done by Gerlis [6]. It is clear to see that alternative assets which include artwork are a significant venture among the rich which explains the boom in the industry and why it set to grow over time.

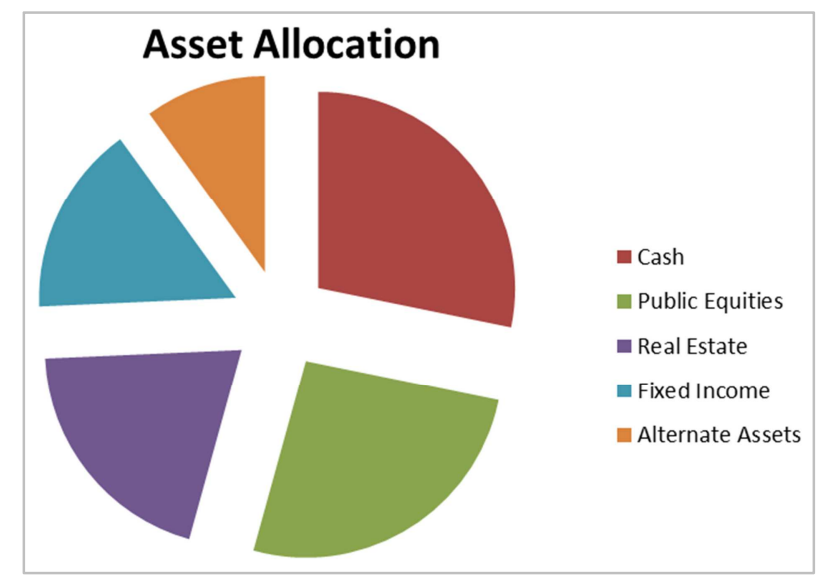

Figure 1. Assets allocation, from Gerlis, [6]. 
Table 1. Comparison of Alternative Assets Value.

\begin{tabular}{llll}
\hline Pleasure Asset & Net worth & Annual Global Sales & Appreciation Value \\
\hline Wine & \$4 Billion & $\$ 35$ Billion & $5 \%-10 \%$ \\
Artwork & $\$ 400$ Billion & $\$ 65$ Billion & $4 \%$ \\
Gold & $\$ 60$ Trillion & $\$ 400$ Billion & $10 \%$ \\
\hline
\end{tabular}

The table above is a compilation of some of the pleasure assets that the ultra-rich are venturing into based on figures adopted from Gerlis [6]. Xiang [16] reports that over $80 \%$ of wealth managers recommend that their clients diversify their investment portfolio by venturing into alternative assets. The table above shows the profitability of some pleasure assets which explains why investors are being encouraged to venture into them. It is clear to see that artwork performs marginally well in the global market and if managed well, can offer handsome rewards.

The art industry continues to garner global attention, a clear indication of growing profitability. This is evident from the success of the various art galleries and exhibitions [1]. Gerlis [6] points out that functions such as galas and art fairs also receive a substantial amount of media and public attention which points to a successful industry. In addition, the art industry operates on a global scale with involvement from American, European and even Asian countries and therefore provides a multi-national market [2]. For the above reasons, investment in art is a safe venture with the promise of steady returns.

\section{Risk Factors}

\subsection{Illiquidity}

For many investors, the illiquidity of artwork as a capital asset is a severe shortcoming that cannot be overlooked. Illiquid assets are characterized by the inability to quickly dispose them off on demand without affecting the asset value. Xiang [16] observes that Artwork often requires high purchase capital and adequate amount of time, at least five years, before the investor is able to make handsome returns on the asset. This works best if the investor is able to freeze a large pool of assets for a long period of time before they can get back gains. While it is possible for the wealthy members of the society, it is a limitation for many mid-range investors who depend on the high liquidity of their assets to accumulate wealth. Gerlis [6] adds that there are complexities that accompany the attempt to sell off art to dealers, institutions and any other buyers. Generally, selling of art is openly discouraged. In comparison, other financial asset such as public equities and even real estate are conveniently liquid and can be offloaded at any time regardless of the amount of maturation time.

\subsection{Pricing}

Art investment requires a high amount of starting capital especially in comparison to other investment fields. Reutter [14] emphasizes that fine artwork remains a luxury commodity both as a commercial good and capital asset. In order to gain substantial rewards, an individual would have to invest a considerable amount of money into the purchase and maintenance of artwork. Xiang [16] reports that members of art funds need upwards of $\$ 1$ million dollars to even join one. Fischer and Arnold [4] point out the additional costs that arise from insurance of the asset, restoration and conservation charges which heighten the risk involved. Currently, the astronomical pricing locks out mid-range investors who cannot avail the amount of capital required to purchase fine art. In comparison, public equities do not require a substantial amount of capital to invest in which leaves room for a diverse group of investors to venture into the stock exchange [6]. As a result, the stock exchange records more rapid growth annually in terms of revenues earned globally because of the larger pool of investors in comparison to the art industry [12]. Similar comments can be made about the real estate which offers a variety of packages to investors and thus caters to both the ultra-rich and the midrange investors.

\subsection{Low Rewards}

When comparing the art industry to other traditional financial investment options, it is clear to see that artwork investment underperforms in terms of rewards. Artwork appreciates at a steady rate of $4 \%$ per annum which is profitable. However, in comparison, public equities appreciate by an average of $10 \%$ annually. Even the wine business and the gold industry which are alternative assets post better returns as they grow by up to $10 \%$ annually. Considering the high risks involved when purchasing artwork in terms of pricing, market complexities and illiquidity, the rewards gained from artwork seem to be unworthy the effort. From an external viewpoint, this reality cannot be ignored by investors and this would explain why artwork rates so low on asset preference. The table below compares public equities which are the preferred form of investment to artwork in terms of appreciation value based on data from Gerlis [6].

Table 2. Comparison of Art Industry Rewards to Other Financial Markets [6].

\begin{tabular}{lll}
\hline Asset & Revenue & Appreciation Value \\
\hline Artwork & \$60 Billion & $4 \%$ \\
Public Equities & \$60 Trillion & $10 \%$ \\
\hline
\end{tabular}

\subsection{Regulation}

A key feature of the art industry is the lack of proper regulation. Gerlis [6], notes that there is a marked lack of transparency in dealings with no clear guidelines on pricing and taxation. In addition, there is marked opacity due to little flow of information. Reutter [14], reasons that the art industry is difficult to regulate due to the heterogeneous 
nature of the product. What qualifies to be fine art varies from paintings, sculptures and architectural designs. In addition, art is produced by a variety of artists, some even dating back to hundreds of years back. This is not to mention the different art movements and genres. This issue is compounded by the lack of a legal framework governing the art industry as with the stock exchange which has a clear guideline on all operations [1]. This makes entry into art investment a free fall especially for someone who does not understand how the industry is set up and it is possible to incur losses.

\subsection{Review}

Deliberation of the risk and rewards associated with art investment shows that the rewards outweigh the risks. As an asset, artwork has outperformed other financial vehicles in term of stability with regards to economic upheavals. This is an attractive feature for an asset because the investor is assured of returns regardless of external factors. The steady appreciation value translates into profits especially if the asset is held over a long time. In addition, the art industry is growing with revenues increasing steadily every year. This shows increased interest in the industry as more wealthy individuals look into diversifying their investment portfolio. The trick with artwork investment seems to be in bidding time as recommended by Xiang [14]. In addition, artwork investment is rightfully classified as an alternative investment because the risks are too high for it to be a first line financial vehicle but the rewards are handsome if it is allowed to mature. Artwork investment requires a deep understanding of the workings of the market whether the investor is an art enthusiast or not. This is because of the irregularity of the market and heterogeneity of the product which leaves artwork value subject to change. Angelini and Castellani [1], remark that the art industry is unique and cannot be subjected to the same standards as the stock market. In addition, the lack of irregularity has not been a barrier to the affluent who continue to grow their asset holdings in artwork. For these reason, the art industry qualifies to be a legitimate investment option especially as a long term investment option.

\subsection{Implications of Management}

Art is classified as a tangible asset because it can be seen and felt. It differs from other forms of investments such as public and private equities. It is hard to compare the management of art to that of other tangible assets due to the typical fragility attached to art. For this reason, Fischer and Arnold [4] reiterate that the value of the asset greatly depends on its physical condition. Artwork therefore requires physical management or it deteriorates in value. Stavnichaya [15] remarks that investment management for artwork starts when funds are committed to the acquisition of the asset. Given that the value of art is largely pegged on authenticity, investors are responsible for identifying legitimate sellers either in the public market during auctions or in the private market from art galleries, exhibitions and other institutions. Being a private asset, the management of art largely depends on the investor. There is the choice of personal ownership or investors can choose to entrust the artwork to professionals for safekeeping as members of art funds do [5]. Either way, high levels of expertise on art preservation is required. Ramsay and Jacobs [12] highlight the importance of investing in art conservation and restoration measures so that the asset does not depreciate in value which will result in losses. Fortunately, since art has been around since time immemorial, there are sophisticated ways of ensuring that the physical state of the art remains intact which is done by professionals. All these are part of the risks that art investment carries so venture into the filed requires dedication on the investor's part.

\section{Conclusion}

With regards to the question posed at the beginning of this paper, it can be concluded that art qualifies to be asset for wealth management. The appeal is in the stable appreciation value especially over long periods of time. It also convenient that art doubles as both a pleasure commodity and a capital asset and investors get to benefit from both qualities. For the affluent looking into diversifying their investment portfolio, the art industry presents a unique opportunity. Further empirical research could be useful to better measure and understand the performance of art as an asset class for wealth management. At this point of time, most of them are conducted by practitioners. They could lack of a certain objectivity in the methods and the results. It is clear the key point is to be able find good data to better investigate the performance of "art" assets compared to other assets classes (mutual funds or other asset classes).

Other further research could be to compare the different arts in terms of economic and financial performance: painting for example compared to sculpture.

The art industry is constantly evolving with changes due to digitalization and new platforms. This last point also opens new fields for research in art and finance.

\section{References}

[1] Angelini, F., \& Castellani, M. (2018). Understanding the artwork pricing: some theoretical models (No. 17-25).

[2] Chang, S. (2013). Art as an investment: return, risk and portfolio diversification in Chinese contemporary art investment.

[3] Coslor, E., \& Spaenjers, C. (2013). Organizational and Epistemic Change: The Growth of the Art Investment Industry.

[4] Fischer, C., \& Arnold, J. (2012). Insurance and the Art Market. Fine Art and High Finance: Expert Advice on the Economics of Ownership, 197-210.

[5] Frye, B. L. (2018). New Art for the People: Art Funds \& Financial Technology. Chi.-Kent L. Rev., 93, 113. 
[6] Gerlis, M. M. (2014). Art as an Investment? A Survey of Comparative Assets. Ashgate Publishing, Ltd.

[7] Goetzmann, W. M, Spaenjers Renneboog L. and Spaenjers Christophe, Art and Money, Yale ICF working paper, No 09/26, Yale University, United State.

[8] Gordon, R., Hermens, E., \& Lennard, F. (2014). Authenticity and Replication: The 'Real Thing'in Art and Art Conservation. Archetype Publications.

[9] Preziosi, D. (Ed.). (2009). The art of art history: a critical anthology. Oxford University Press, USA.

[10] Rachel A. J. Pownall (2020), Art as financial investment, Tillburg University, Department of Finance, working paper.

[11] Rachel A. J. Pownall and Christian Wiehenkamp. Art backed lending: implied spreads and Art Risk Management, 2020, Tilburg University - Department of Finance; Maastricht University - Department of Finance, working paper.
[12] Ramsay, B. A., \& Jacobs, J. K. (2012). Art Conservation and Restoration. Fine Art and High Finance: Expert Advice on the Economics of Ownership, 263-286.

[13] Renneboog, L., \& Spaenjers, C. (2013). Buying beauty: On prices and returns in the art market. Management Science, 59 (1), 36-53.

[14] Reutter, M. A. (2001). Artists, Galleries and the Market: Historical Economic and Legal Aspects of Artist-Dealer Relationships. Vill. Sports \& Ent. LJ, 8, 99.

[15] Stavnichaya, A. (2011). Art Investment Portfolios. Arcad Business School, Helsinki, Finland.

[16] Xiang, A. (2017). Unlocking the potential of art investment vehicles. Yale LJ, 127, 1698. 